\title{
Beyond Collapse: Reclaiming Rationality and Scientific Method from the Global Disorder
}

McMurtry

Follow this and additional works at: https://scholarlycommons.law.case.edu/swb

Part of the Human Rights Law Commons, and the Social and Behavioral Sciences Commons

\section{Recommended Citation}

McMurtry. 2009. "Beyond Collapse: Reclaiming Rationality and Scientific Method from the Global Disorder." Societies Without Borders 4 (1): 73-93.

Available at: https://scholarlycommons.law.case.edu/swb/vol4/iss1/6 


\title{
Beyond Collapse: Reclaiming Rationality and Scientific Method from the Global Disorder
}

\author{
John McMurtry \\ University of Guelph, Ontario, Canada
}

Received 15 February 2008; accepted 20 March 2008

\begin{abstract}
This analysis explains why the currently instituted value-sets of "rationality" and "scientific method" select for unforeseen consequences of economic, social and ecological system collapse. Laying bare the era's unifying paradigm of "rational choice" across theory (e.g., game theory, contractarianism, prisoner's dilemma) and practice (global business, geostrategic analysis, armed war and mass-media sport), the analysis exposes the systematic disconnection of rationality and its lead vector of scientific method from the needs and capacities of life-systems. Only if rational and scientific standards are grounded in life-enabling purpose and means consistent with it, the argument shows, can they be made coherent with life support systems through generational time.
\end{abstract}

\section{Keywords}

civil commons, game theory, life-blind logic, life support systems, rationality, scientific method, value syntax

\section{The Problem}

Perhaps only the wilfully blind remain oblivious to the challenge humanity now confronts. The air, soil and water degrade, climates and oceans destabilize, a rising half of the world is destitute, public sectors and services are privatized for profit, and species become extinct at a spasm rate. Yet there is little explanatory connection across these phenomena, and no evident understanding of the "rational and scientific" regulators themselves which select for rising disorder across ecological, economic and social domains. ${ }^{1}$

1) This set of life-organization breakdowns is documented, connected across phenomena and explained at the level of the "money-capital sequence of value" as external system decider, with the observation that assumed "neutral" biological and ecological sciences as 
The principles of "rationality" and "science" themselves are not called into question because their standards are assumed to be inherently "rigorous" and "value free". They are above intellectual or practical question. That their inner logic itself is structured towards cumulative global collapse is not conceived as a possibility. Since review of the received literatures does disclose this meta problem or its a-priori structure, this analysis is written (1) to expose that exact structure and (2) to adopt a life-grounded baseline to which existing models of rationality and scientific method are blind, including critical theories of "instrumental reason".

\section{The Game Paradigm of Rationality}

The inner logic of rationality by which the current global end-game is driven can be found in the formal structure of game theory itself, the lead paradigm of rational choice in our era. Its model is possibly the most richly funded area of study in the decision sciences, and the largesse of the US Department of Defense has supplied lucrative research grants to the field since the Second World War. ${ }^{2}$ Even formalist philosophers and social scientists with no such direct funding have developed discourses based on the model upon which countless careers have been made and pursued over 50 years. More fatefully for societies, the game-theoretic model frames the calculations and general thought-system of corporate business strategies and state military policies across global borders.

At the unexamined core of received models of rational choice of power is an axiomatic principle which much symbolic notation and formal jargon conceals across disciplines and domains. It is taken for granted as a formal given. Neoclassical economics, contractarian and decision theory assume it as an axiomatic first principle. The ruling concept is so simple and fundamental that it is assumed as proceeding from the laws of thought and nature at once - an ordering mechanism independent of human will. Yet analysis discloses a value syntax of rationality which is presupposed beneath conscious reflection. It illicitly assumes a five-step sequence of premises which are nowhere critically examined or allowed question: namely, (i) self-maximizing strategies in (ii) conditions of scarcity or

well as environmental philosophy and ethics block out this causal structure of the problems they study (McMurtry 2002, pp. 180-192).

2) Mirowski 2000 . 
conflict over (iii) desired payoffs at (iv) minimum costs for the self to ( $v$ ) succeed or win.

This is the unrecognized meta-program of "rationality" (MPR) in this era. Its normative structure, however, is unexamined. More fatally, it is not connected to the collapse of global economic, social and ecological systems which it leads as a regulating vector. Since its axiomatic frame is assumed a-priori, any alternative to it is inconceivable. The test of the truth of this high-level abstraction is to try to find clear exception to this regulating meta program in any ruling decision structure across disciplines, institutions and domains of power.

Unhappily, the instituted framework of academic freedom itself is not free of the silently coercive governance of the ruling axiom set. The academy careerist chooses a self-maximizing career path where many compete for scarce goods to achieve rank and income over others at minimum cost to self as the given framework of the profession - all in perfect accord with the MPR. "What choice is there?" The question itself reveals the rule of the disorder. In truth, the academic vocation clearly entails an opposite set of regulating principles: (i) maximization of learning advancement and dissemination by (ii) knowledge sharing without limit for understanding as value in itself at (iv) any cost of difficulty to (v) develop humanity's more inclusive comprehension of natural and ultimate human phenomena.

Consider the implications of this systematic opposition of the ruling paradigm of rationality to the very vocation of higher learning and research. That it has not raised a barricades of resistance within the university community and its public funders discloses the unseen depth of a mindless takeover.

\section{Recognizing the Life-Blind Logic}

While nowhere formally noticed within its libraries of literatures, perfect indifference to life value is built into the ruling model of rationality in all its forms - from the corporate market to geostrategic planning war to public-sector peck-orders. For momentous example, "the war against terror" is justified in terms of "national self-interest" whose meaning never wavers from conformity to the MPR, while itself imposing a globalizing terror mechanism to maximize asset payoffs to dominant players. ${ }^{3}$

\footnotetext{
3) McMurtry 2007a.
} 
At the civilian level of conformity to the MPR, market gaming to minimize money costs and maximize returns of monetary value can lead, and has led, to numberless deaths, diseases and casualties of consumers and others as "rational decision-making", and, in all, a global degradation of well-being. ${ }^{4}$ The positive trade-off is always believed to be greater supply of "goods for consumers", and thus their self-maximizing interest as well as of investors. What is overlooked is that the goods produced in strict accordance with the MPR are not "goods" as assumed a-priori. They are usually $b a d s$, in fact, for people's lives and life conditions by their extraction, production, transport or consumption. This is not a play on words, but discloses a ruling axiological syntax which inverts reality into its opposite to conform to its first principles. Consider in this light most fast and processed foods sold in the market today, or the world's most profitable commodity of manufacture, non-defensive armaments. They are bads in fact because they typically result in ill-being rather than well-being by their manufacture, transport, consumption and waste. But the ruling name of "goods" reclassifies them as the opposite, and - most revealingly - this systematic normative inversion remains unchallenged as a positivist rational category.

Thus the formal descriptors of "goods produced" and "welfare added" remain assumed by economic texts and government accounts across borders as representing positive facts of "empirical science". With life effects nowhere taken into account by such "scientific rationality", ever more asserted "goods" and "welfare" are, in truth, ever more ills injected into human and environmental life-systems. Many critical analyses now catch the downstream ill effects by empirical inquiry and documentation. Yet understanding has not moved back to the more primary level of the categorical framework of the ruling scientific rationality itself, even less to the regulating ends assumed by formal reason. Thus profusions of junks, chemically/ genetically-engineered concoctions and violence commodities increasingly proliferate as "goods" with no life standards applied at any moment of "value-adding chains" - from corporate strategic plans and scientific laboratories to the public policies of political, economic and environmental management further assume the system as rationally "self-regulating".

Any truly rational or scientific claim or action is open to disconfirming argument and evidence. This is called the principle of "fallibilism" in philosophy, and "falsifiability" in empirical science. No such principle, how-

4) Weisbrot et al., 2006, track this general degradation in the last 25 years of "globalization". 
ever, now applies to market "goods" or "economic welfare" at any level. Consequently, "optimizing strategies of competition" and "efficiency" produce ever larger numbers of deformed lives, toxic products and casualties with no regulating feedback to modify the system, even at the level of the problematics of high theory. The ruling value syntax which scientific rationality serves is presupposed as given, and so life-blind prejudice rules "Science" too beneath awareness of the problem. That is why the gravest observed degradations of life and life support systems levels do not compute in public and national accounts of "standards of living". It is also why ever more extractions, manufacture, transportation and sales of life-disabling methods and products are pursued by the physical and biological sciences and advanced technology to lead "essential economic growth" and "better lives for populations".

In this way, epistemic and moral disorder is built into the principles of "rationality" and "science" themselves, but with no recognition of their internal derangement.

\section{The Groundless Pluralism of Selves}

No remedy may be found in the reflections of high theory. As contemporary liberalism and postmodernism celebrate a "pluralism" of values and voices, formal decision and game theory led by contractarianism perfect a theoretical framework of meaning in which all value is found in what abstract selves seeking maximum payoffs possible for their positions decide by rational deduction in life-emptied logical choice spaces. Almost all the principal names in economic, social, political and moral philosophy have adopted this ruling formula of rationality as axiomatic. The principle of "Pareto optimality", coined by Vilfredo Pareto (1906), A Theory of Justice (1971) by John Rawls, and Morals by Agreement (1986) by contemporary philosopher David Gauthier are notable examples. ${ }^{5}$

Insofar as this disconnection of "rationality" from any life-ground of value is not reflectively considered, a virtual world comes to substitute for

\footnotetext{
5) These classics of twentieth-century economic, political and moral theory all presuppose this meta program of self-regarding maximization as rationality, and it includes "to want a larger share for oneself" (Rawls 1971, p. 143), "no upper bound [of the self's appropriation]" (Gauthier 1986, p. 318), and no preclusion of a few having all assets and most having only debts (an unexamined possibility of the cornerstone principle of "Pareto optimality" first articulated in Pareto 1971[1906]).
} 
the real one as the given choice framework of the ethical, economic and political thought of the era. There are no life conditions, children, life community, or other species left in industries of volumes on "rational choice". Yet this life void does not disturb theorists or models, especially not neoclassical economics. What is ruled out a-priori is invisible.

A "postmodern" reaction has occurred over 40 years against universal, rational paradigms - but not because they are life-blind, but because they are universal. In the postmodern escape from the authority of reason, only "differences" remain, and they are essentially restricted to linguistic circuits. Most postmodern theory itself preconsciously presupposes the ruling order of consumer capitalism as its unseen model. ${ }^{6}$ Whatever individuals want is their right to assert, "the consumer cannot be wrong". Some like Gilles Deleuze challenge capitalism, but for him the only liberation can be by "schizoid deterritorializations" of ubiquitous capitalist flows in "madness escaping control on all sides, and carrying us along"?

Both "rational" and "postmodern" thought frames thus covertly concurs in what they rule out. Neither liberalism nor postmodernism - let alone neoclassical economics - can in principle comprehend the common life grounds by which selves are made possible prior to consumer preferences, postmodern voices or rational choice schedules. All schools of meaning and value become based on disconnected selves - at one pole, formal, logical and atomic selves, and at the other pole literary, polyvocal and euphoric, but all submerged in self-maximizing sequences decoupled from life means and conditions. The emergent world crisis and its regulating meta program are blocked out a-priori.

\section{Prisoner's Dilemma: Life-Disconnected Rationality as Paradigm}

Perhaps the single most famous paradigm of the theory of atomically maximizing selves is "prisoner's dilemma" which has singular pride of place in contemporary formalist philosophy and the social sciences of economics and psychology. It is so entrenched as a paradigm of rational choice and the paradoxes it generates that its authorship and influence can no more be confined to one individual than an instituted frame of mind. In this model, pre-set choices are boxed into one set for two players who have no possibil-

\footnotetext{
6) McMurtry, 1980, pp. 228-238.

7) Deleuze 1977, p. 246.
} 
ity of communicative cooperation - a formal metaphor of the atomic structure of alienation from common life interests which rules as the era's framework of value decision.

The dilemma which the atomic choosers confront is whether to "defect" (confess), or not. If one confesses and the other remains silent, the one who turns coat goes free, and the one who remains in solidarity gets ten years. If they turn on each other for self benefit, they get five years. If both remain silent, they each get a light sentence of two years or less. What does one rationally do as a self-maximizer? That is the only dilemma.

On a deeper level than a-priori acceptance of such premises, the dilemma arises because the ruling value frame is constructed as a closed box. Selfmaximizing decision is locked into a choice space void of all life substance and relations. "Reiterated", "n-person" and "free rider" variations on selfmaximizing atomic individual fill journals and books across specialties and disciplines. All conform to one value syntax. Co-operative unities of persons grounding in common life interests are ruled out a-priori. Thus the civil commons infrastructures on which society is based - social constructs which enable universal access to life goods from everyday language to oldage pensions - are abstracted away on both planes.

The collapse of social and natural life infrastructures can follow from this self-maximizing atomic "rationality" with no life-coherent notice. This is why social programs of all kinds are attacked as "unproductive" and "unaffordable", and liquidated for "efficiency" and "development" - that is, for self-maximizing results in money and commodities alone. The world is stripped down to this procrustean metric as "necessary rationalization" which proceeds in accordance with the master axiom as if by physical laws.

In a poignant but unremarked symbolization of the wider social conditions within which the paradigm of prisoner's dilemma is presented, all the relevant coordinates of the crise de choix are blanked out - what the criminal accusation is, whether either party is guilty or innocent, the justification or conditions of being prison-caged itself, and anything to do with examining the human purposes and life values by which a sane humanity or society governs itself. Erased Kafka-like from the story, only atomically self-serving preferences rule as "rational".

In reality, there are self-evident life values demanding public clean water, an unpolluted environment, and other collective goods at every level of human existence. But none can be decided for from within this locked frame of atomic choice without problems of "free riders", "paradoxes of 
aggregate preference" and other doctrinal blind alleys stopping thought $-\mathrm{a}$ predicament classified as "the problem of collective choice" over 50 years of confronting the a-priori walls of confinement. Since all choosers are selfmaximizers by nature, collective life values and decisions are blocked from comprehension and implementation within the thought system.

Ten regulating principles implicitly govern the ruling choice framework which is conceived as "the natural competition of selves" with all "seeking the most they can get". These governors are silently presupposed across evolutionary biology, economic theory, political science, positivist sociology and rational decision matrices in general. They constitute the priori value syntax of the MPR .

(1) All agents seek only to maximize their own preferences.

(2) Each agent's preference-object is fixed.

(3) One's competitors in the game are not subject to choice.

(4) One can appeal to no standard of justice or right external to the game-structure.

(5) Each player's position is preordained independent of moral desert or life need;

(6) All choices and outcomes are prescribed in advance.

(7) The preference order of payoffs and losses is inalterable.

(8) No concern for anyone else's interests can influence choice save by its impact on one's own payoffs or losses.

(9) No decision may be related to any relationship or tie of the players beyond the game.

(10) No payoff received relates to life contribution or need.

Together these regulating presuppositions constitute the unstated value-set by which the military, the market and other instituted orders are governed on the ground as well as, more purely, on the level of theoretical representations whose function is reduced to perfecting the life-decoupled matrices. This a-priori format determines the ruling meanings of human purpose, competition, means and end relationships, positional determination, value ranking, and the bottom-line of desire - in all, the ruling framework of "rational choice" in this era. Transnational corporations, national military hierarchies, political parties and sports teams all conform with no question of the meta program.

One may, revealingly, put a proletarian worker into the choice space of atomic agent, and find the same system demands. One invisibly ruling 
choice frame joins all in one value syntax of life-blind calculation. All are expected to self-maximize; to prefer always more to less money; to compete in the market with whomever desires what one also wants; to know that there is no standard of value that can overrule the rules of the game; to accept that one is born into it and goes where one is assigned with no moral claims beyond its order; to accept the options and outcomes as they are set to maximize one's own position; to hold one's course of choice consistently to succeed; to not worry about others or what is not your assigned job; to stick to one's place within the given order; and not to expect that any who are better positioned have contributed more to human life or need what they have.

This is the elaborated framework of the MPR, spelling out the original five-step formula as ten commandments of how all are supposed to think and live. From market and geostrategic calculations to high theory and entertainment games, one syntax of "rationality" and "rationalization" rules with life connections stripped out. Life vocation, means and life support systems are all excised from rational calculus, while abstract individual and institutional selves are set to demand ever more for their possession of whatever asset is at stake with no limit except other selves rationally seeking the same as a law of being.

\section{System Collapse: Blocking Out System Cause-Effect}

The International Forum on Globalization (IFG) consisting of academic researchers, economists, non-governmental administrators and writers representing over 40 organisations from 20 countries had these general facts of life-systems crisis to report a decade ago, to which no policy formation has effectively responded since: "The pattern of recent years has been - massive economic breakdown in some countries, growing unemployment and dislocation in all regions, direct assaults on environmental and labor conditions, loss of wilderness and biodiversity, massive population shifts - conversion of [water, forests and soil] to luxury commodities increased hunger, landlessness, homelessness - and insecure food supplies, lower food quality and contaminated foods as secondary outcomes". ${ }^{8}$

These cascading losses of life bases form an underlying pattern across domains, but have not been connected back to their upstream determiner,

8) International Forum on Globalization 1998. 
the ruling meta program of "rationality" which inexorably selects for them while blinkering out the effects as "externalities". Ongoing collapses of aquifer reserves, ocean fish stocks, coral reefs, forest habitat, primary arable land, nutritional contents of processed foods, tolerably quiet zones, and songbird numbers are not connected. Nor, more deeply, are they tracked as unseen effects of "rational choices" for self-maximizing payoffs not grounded in life values at any level.

The causal structure at work is beyond the comprehension of the closed thought regime. The system-wide connections and simultaneous breakdowns are unthinkable to it. As the deepening and widening profile of cumulative degradation of life support bases and human life quality becomes undeniably manifested in biophysical reality, the shared framework of rational planning which govern corporate, scientific and policy bodies remains paralyzed within the life-blind mechanism of the system. Throughout it is assumed as "rational" and "scientific", with even critical analyses focusing on foreground policies, wages levels, or specific ecological disruptions.

Striking symptoms illustrate the breakdowns of life means supplies and supports following from the advocacies of "economic science" operating on the bases of "self-maximizing rationality" as ultimate decider. For revealing instance of the multiple interconnections at the system level, as staple food prices escalated in 2007 (principally maize) and a long-term food crisis was preconsciously engineered by government-subsidized conversions of farmland in tens of millions of hectares to produce "agrofuels" for private gas tanks by increased net consumption of energy and reduction of food stocks at the same time, the flagstaff journal of global economic trends, the September 82007 Economist, approvingly reported that the U.S. Clean Water Act allows more pollution than its regulations permit so long as the polluter "is able to show that more filth is necessary to produce an important economic or social benefit". Again we may see behind the diverse and destabilizing phenomena one ruling syntax of "rationality" stripped of all life purpose in principle - with even ecogenocidal consequences undetectable through its regulating prism.

A simultaneous and far-reaching decline in the vocational capacities of the human species across borders goes unrecognized behind the growing disorder of economic, social and ecological systems. An undeniable but unreported fall in life-serving vocations is selected for across cultures by the "inevitable processes of rationalization" - which always means, decoded, maximally swift conversion of all forms of life to money-and-commodity sequences. Rural soil resources, local agriculture and farming vocations in 
the world's system of food production, ${ }^{9}$ and, simultaneously, social services and the caring professions in urban centers are stripped of income and funding to "promote productivity", while the systematic hollowing out of meaningful employment of life value to others is ignored across urbanrural splits and cultural borders. ${ }^{10}$

The tightening vice of "rationalization" on global life on every plane proceeds in lock-step conformity to one meta program to which the most dehumanizing and destructive life effects do not compute. Masterful class analyses such as David Harvey's are correct as far as they go $;{ }^{11}$ but they do not consider the deeper derangement of human reason behind the classdivided effects. The system decider of "scientific rationality" defines the axiomatic givens, the regulating categories of meaning, the parameters of observation and exclusion, and - in all - the structural disconnection of organized human thought from life and life support systems in the ends and means assumed as given.

\section{True versus False Rationality}

Rationality must have an objective and be consistent with it to qualify as rational. That is well known. The unseen problem is that the rational objective assumed by the ruling program of false rationality, and the objective of enabling rather than disabling life adopted by true rationality, are opposite in principle, but without recognition of their exact contradiction. At the regulating core are the maximizing purposes of life value versus non-life value, and the means by which their opposed ends are best achieved. No such distinction of ends or means now exists for rational choice models because they are in principle indifferent to it. Since the regulating objectives of loss and gain are opposite, one life-blind and the other life-serving, the long-term cumulative outcome is chaotic. Distinction between what consistently enables and what systematically disables life systems is screened out in the deluded assumption that this is "science".

At the core of the derangement, the given value metric of money units, homogenous and life-insensitive, has become the lingua franca of rational choice: that without which the bearers of the ruling meta program cannot think. Hence the adoration of mathematical method to which money

\footnotetext{
9) Sumner 2006.

10) McMurtry 1999.

11) Harvey 2005.
} 
sequences are perfectly suited. Per capita income and welfare "growth" are, in consequence, crudely conflated, although they are contradictory in regulating values - one referring to gross national money transactions (e.g., by more junkfood sold) and one referring to life value added (e.g., by less junkfood bought). At bottom, this is "the growth confusion" which leads the collapse of the planet's life support infrastructures.

The unseen value contradiction of objectives and processes can be formally defined. The life sequence of value (Life $\rightarrow$ Means of Life $\rightarrow$ More Life, or $\left.L->M-o f-L->L^{1}\right)$ is increasingly subjugated by the money sequence of value $\left(\$->\operatorname{Las} M->\$^{1,}\right)$, where life is made means to more money. There are countless variations on the money and life sequences of rationality, of purposes and consistent means to their realization. Yet the former is always life-disabling in long-term process and effects, and the latter is life-enabling in regulating principle. With no way within the received concepts of economic or other rationality to define their contradiction, the life-ground of rationality is blocked out and blindly overrun. ${ }^{12}$ We do not have room here to show how from Adam Smith and David Hume through Max Weber and Karl Marx to J.B. Jevons, F.A Hayek, Milton Friedman and Jürgen Habermas, rationality is nowhere regulated by life-coherent reason - that which rules out such contradiction as invalid.

The global consequence is that human lives and life means are systematically reduced to functions of life-indifferently expanding money sequences of value, and thereby subjugated, degraded, poisoned, exhausted, deracinated or otherwise de-lifed to fit the imperatives of the ruling system objective of "more economic growth by maximally efficient means" - the set-point of "rationalization" which the paid sciences serve. Because this fatal conflict within the ruling paradigm is invisible, it is neither recognized or responded to.

From the more consistent standpoint of terrestrial life, however, true and false rationality can be distinguished. True rationality is grasped only insofar as it meets three regulating criteria, the third of which has been prescinded by ruling dogma and power:

12) Marx (1867) identifies the "capitalist formula" (M(oney) $\rightarrow \mathrm{C}$ (ommodity) $\rightarrow \mathrm{M}(\text { oney })^{1}$, but he explicitly identifies its contradiction with "the stage of development of productive forces" if and only if the latter has "outgrown its capitalist integument". McMurtry, 1998, 1999, 2002, identifies the opposed regulators as, more basically, between money and life sequences of value as defined here, but conceives the outcome as not lawlike, but determined by contingent and socially constructed regulators, including rationality and scientific method themselves. 
(1) to adopt fact-consistent premises;

(2) to ensure valid inferences from them and

(3) to enable rather than disable life as regulating purpose.

(1) and/or (2) are the traditional standards of science and logic respectively, although the latter has formally abandoned empirical bases. More fatefully, standard (3) has been systematically disregarded by confinement to objectives indifferent to effects on life systems. Rationality has thus become a mechanism of partiality confined to the self-serving demands of its funders and their narrow parameters of prediction.

No-one can coherently deny these three requirements of rational thinking or reason. It cannot be rational to ignore or flout empirical evidence, to be inconsistent in claim, or to follow a life-blind purpose. Yet reason's three-fold requirement of consistency with facts and other statements and life purpose is nowhere required by the received standards of science or rationality.

\section{Comprehending the Derangement of Rational Choice}

A native proverb, attributed to Crowfoot (1830-90), identifies the valuesystem decider behind the long-unfolding collapse of global life systems. "After the last tree has been cut, the last river has been poisoned, and the last fish has been caught, they will recognize that you can't eat money". Crowfoot's conclusion has an explanation. False value equations are built into decision structures, and rational self-maximization subjugates the world to them. "Value added" means profitable margins of sale within moneysequences rather than more life-enabling goods. "Enhanced welfare" means the profitable sale of priced commodities, not life gains by consumption or use of them. Mechanically steering for money-sequence rather than lifesequence advance at micro and macro levels, the ruling meta program has no capacity to distinguish between ill-being and well-being of life-systems by its operations or results. Not even the cumulative collapse of life systems on the ground over generations deters the certitude of "development" and "increased welfare" as long as the life-blind paradigm of scientific rationality remains the decision governor.

There are many symptoms of the ruling disorder of rational regulators. "Work" is what reaps money returns, and if it does not, it is "economically inactive". "Moral hazard" is not what harms people, but the non-payment of money demands on time. Value "securitization" is by money derivatives 
grounded in people's homes subject to bank seizures. Social orders are overturned for "unobstructed capital and commodity flows". "Security" is the protection by force of arms of private money-sequence demands against collective 1 life resistance.

The generic core of the derangement is built into rationality and scientific method themselves. Insofar as theories, left or right, exclude from account life needs and life support systems, the laws of motion of the moneysequence mechanism they observe, perfect and extend becomes a mechanical demiurge whose imperatives are assumed as beyond human choice. They are, to use Karl Marx's own terminology, "independent of human will". ${ }^{13}$ The ecogenocidal rule appears to be necessitated in virtue of the system compulsion it exerts. What is inconceivable through the "rational" regulators is life value itself. This is why, incredibly, the concept of human "need" - that without which life capacity is always reduced - does not exist in received scientific lexicons or their measures (i.e., Neoclassical or Classical Economics or the Social Sciences in general). Rationality which is lifeblind is absurd, but the absurdity cannot be recognized within the MPR.

As human and natural life and life support systems are drawn down by "rational economic growth", concerns arise from within established quarters about overstepping natural bounds. Thus analyses such as The Limits to Growth by the Club of Rome ${ }^{14}$ and Our Common Future by the World Commission of the Environment and Development ${ }^{15}$ recognize a general problem of system overreach, but nowhere connect back to the systemdeciding problem. A much favoured explanation is the planet's rising population numbers. Yet because uncontrolled population increases are abstracted from the conditions of mass poverty and industrializing conditions producing them (with negative endogenous growth in welfare-state conditions), the cause-effect relationships are blocked out, and only the symptom is seen. The exponential growth of the money sequence commandeering all else is, moreover, not related to the exponential growth of impoverished populations. With no grounding in the life-blind system selecting for the ruinous effects, they cannot be comprehended in their deciding mechanism of end and means.

13) Marx 1859, Preface.

14) Club of Rome 1972.

15) World Commission of the Environment and Development, 1986. 


\section{Life Support Systems as Ground of Reason}

When "two thirds of the natural machinery supports life on Earth has already been degraded" (as documented in a report of 1,360 scientists launched at the Royal Society of London in April 2005), human civilization palpably meets a turning point of re-grounding rational deciders, or destroying the planetary life-host. Yet even in world-expert recognition of a draw-down crisis, the problem is posed as one of "degraded machinery". The meaning of life support systems themselves is bracketed out. That their infinitely interconnected life webs and support systems are the opposite of machinery - they cannot be put into reverse or replaced in all components - does not compute. Recognition stays within the reversible mechanical model even as it structures towards terrestrial life collapse.

As a result, the very means and foundations of human life which have been progressively built as the bases of the species' survival and development do not count into scientific or economic accounts. Yet across polar extremes of government, underlying life support systems have been planned and built piecemeal without which human life is reduced to misery and death - functioning water and sewage infrastructures, everyday health norms and technical support systems, enabling literacy and educational development of citizens, and common life spaces of culture and nature. This is the "the principle of the civil commons" at work in historical evolution, but amnesiac in contemporary theory, policy and practice. ${ }^{16}$ The rational first premise of public policy and scientific advance, the common life-ground, is not anchored in or conceived. Evolution of the life support systems of which the civil commons is the agency is what distinguishes human reason from the beginning. Yet concealed by sectarian politics and consumer demand cycles, they are under-funded, privatized, deregulated, theoretically blinkered out or otherwise neglected rather than built upon as the very foundations of rational human life and scientific project.

What is irrational at the very baseline of the human condition is that there is no principled criterion or connection among these shared life support systems to distinguish them from ever more dominant systems of life-means deprivation and civil destruction - like the billions of dollars a day the public pays to fuel the very military and corporate mechanisms which lead the global deracination by armouries of science with no

16) McMurtry (1998, 1999, 2002) and Sumner (2005) define the "civil commons" as "any and all social constructs which enable universal access to life goods" - from language to city squares. 
accountability to life purposes. In truth, life support systems are the universal benchmarks of worth by which social systems can be rationally measured, and their true "standards of living" rationally judged as rising or falling across all borders. These true living standards are, however, screened out by financial or asset-gain measures with no life coordinates. Universal human life values - quality of air to breathe and working conditions that do not kill, maim or cause disease, life security and care of the helpless by age, disemployment or disability, access to cultural goods and expression, and biodiversity of flora and fauna across regions - are, instead, confined to rhetoric while being despoiled in the name of "rising standards of living" themselves.

Although in fact every life support system, from clean air and water to public pathways to universal education, has evolved by a life-grounded rationality, this ultimately regulating basis of society's life and development, the civil commons, is ignored in its meaning, and the social constructs enabling citizens' universal access to life goods are themselves systematically defunded and privatized to serve atomic money-sequence objectives instead. Even the theoretical left overlooks this common life-ground in systematic focus on class interests based in rights of ownership - specifically, the owners of labor and capital - with the logic of self-maximizing strategies in conflict to gain at others' expense raised to another level. This is the central blind-spot of Left and Right understanding. It explains how social and natural life support systems can be devastated underneath class and other conflicts over a century with no principled anchoring in common life-ground to recognize the system problem, or to scientific ground rationality in life purpose. Mass sacrifice of lives and life conditions can proceed as "necessary" for old or new political programs with no anchoring of rational judgement in the life support systems of all.

The life-enabling purpose and consistency of means required of any coherent scientific rationality thus remain locked out: while collective life support systems degrade and collapse beneath by forces of "rationalization" agreed to across governing parties and civilizations.

\section{Beyond Cooked Science: Reclaiming Rationality and Scientific Method}

Scientific method is a set of collective standards whose meaning is not to serve special interests, but to discover the truth of hypotheses in explaining 
human and natural phenomena. If, in contrast, research and learning are valued for "competition in the global market", a conflict of interest arises. Science and scientists are obliged to be unbiased in research goals and to take into account all contra-indicative evidence in results. Yet for-sale research to "develop profitable products for market" selects out research objectives and evidence that do not fulfil this goal - for example, massive academic research into carcinogenic additives of commercial products, or Southern diseases like malaria and dysentery whose victims lack profitable market demand.

There have been growing debates around this nest of issues - whether pharmaceutical and medical corporations have hijacked medical science as a servant function to their own profit agenda, whether students conceive their education as merely a middle term for selling themselves at a higher price, and whether higher education has become a handmaiden and patent player of corporate money sequencing with universities as their publicly funded resource. The critical literature here is disparately immense, but without any clear common ground of the end and means of reason. Nonetheless, one underlying question to any scientific investigation or technological development reveals the integrity of its scientific enterprise which scientific rationality by its nature is obliged to show. Does the scientific objective and method include its coherence with life support systems by its proposed advance? This question is not asked, but its answer is no. No regulating standard to select for rather than against human and environmental life support systems is yet built into the scientific protocol of any current research domain.

In more systematic terms, the structuring of scientific method and research is as blind to harm to shared life support systems as the private corporate and state military funders of them. For scientists must conform to the same objectives as their funders to be selected for support - including by designing the capacities to maim and destroy countless people and their life infrastructures (e.g., by weapons research which appropriates approximately $60 \%$ of U.S. federal research funding). The leading edges of science are thus subserved to the world's most life-destructive interests with no standards of scientific accountability beyond them.

As the principles of scientific method now exist, scientific and technological enterprises exhibit an undetected value-system profile. They exclude the premises of life support services from account, rule out accountability for ill effects as a "political responsibility" while jealously guarding "scientific independence" in subordination to funders, and systemically structure 
goals and methods to serve private commercial interests and armed-force advantage. These blind spots are built into regimes of "high-tech research" in particular - a regulating pattern which is taboo to question as a condition of selection for funding. In the macrocosm as well as microcosm, the scientists and scientific bodies sustaining this invisibly regulating value system of their work receive the lion's share of wealth for research, while no principle of scientific method rules out a servant role to the life-blind mechanism which rules. Contra-indicative results demonstrate that systemic life hazards are variously silenced or kept beyond the reach of law (eg., in pharmaceutical and genetic-engineering research and top-secret military projects), while the meta pattern of cooked science is not detected across borders.

"Defence" or war against designated enemies is the justifying rationale of military-industrial and geostrategic sciences on the public plane. "Managed risk" is the rationale for overriding life standards in state and corporate sciences. These forms of "science" and "rationalization" are now taken for granted, while prior requirements of serving the public interest are removed to "lower/rationalize cost inputs". The elementary standard to ensure against such instituted biases is the rule of scientific integrity. Its principle is straightforward. Any science in which the funder or partner has a financial stake in the outcome of the research is invalid. Only results by independent scientific tests qualify as good science - a requirement increasingly abandoned by government agencies and university scientists.

Until such a general standard of scientific impartiality is introduced, science is subjugated to external and partial interests and demands "to receive funding", and non-compliant research is accordingly selected out of financial support. Non-funding is a sentence of death to most scientific research, and if it is not allowed to be independent of such distorting pressures on objectives and results, a life-and-death threat remains implicit in the research regime. Either scientists serve the external special interest, or they do not survive. This is an offer that can't be refused. It abolishes impartial science as effectively as medieval Church control, but with far greater dangers to life support systems by technological powers.

The very nature of scientific rationality - to inquire and observe without bias of non-scientific objectives and with no selection of results to suit non-scientific demands of private gain - is thus usurped. More fatally, cumulatively disastrous results to organic, ecological and social life are the systemic outcome. Either the standards required for science to be science are reclaimed, or the ruling global regime of rational choice and scientific 
technology continues to disaggregrate and reassemble human life and the conditions of human life as place-holders, commodities and wastes at ever higher volumes and velocities.

\section{From Scientific Integrity to Impartial Predictive Capacity}

The second standard of scientific inquiry required to overcome this meta order of cooked science is no less basic. It corrects the ruling blindness to contra-indicative results which do not fit the ruling order. Here again, the principle of scientific rationality is self-evident once identified. Predictive capacity is extended beyond external funder interests by binding precautionary principle within scientific method itself. Science's power to predict is tested at the level which counts most - the anticipated and tracked effects on life support systems prior to insertion of new causal mechanisms into them.

In contrast, subordination to the rule of reduced costs and increased revenues for private money-sequences rules out such a precautionary principle a-priori - the second level of anti-scientific distortion built into the current system. The rational solution is again straightforward. It is to require research objectives and designs to select against ill-effects on life systems before research or application proceeds - the physician's principle of "no harm" applied to science in general, a long tried-and-true principle of accountability to human life and knowledge requirement. Only in this way does scientific method fulfil the evidential and predictive demands of good science, while also fulfilling the major criterion of rationality to consistently enable rather than disable life as end by the best means available.

Neither basic scientific standard, however, stands a chance of implementation without binding public funding directives. Thus the most lavishly funded science continues to fashion more efficient weapons for use against citizens and life support systems; chemical and genetic engineering of toxic food inputs across the production-consumption cycle with few effective standards of prevention; and for-profit intervention in already existing cancers or disasters whose manufactured and scientifically contrived determinants are not investigated or controlled.

Commercially regulated research, testing and application is in these ways deformed in principle. Yet simultaneous exclusions of evidence and avoidance of downstream results are not just bad science. They have systemic 
effects of morbidity and death to countless people and their life conditions by the bad science. What is directly implanted into human and natural life-systems is not scientifically tracked in effects, from new dominant genes and non-bio-assayed chemicals to mass sales of deadly arms and products. "Rational self-maximization" by "scientific and technological discovery" are, thus, not merely incoherent in logic. They are globally pathogenic in structure.

As the merely commercial standard of "the more sold, the better" increasingly dominates current government agencies and universities who mimic the scientific unaccountability of "managed risk", they themselves contravene scientific rationality at the core. They literally "do not know what they are doing" while failing at the defining capacity of modern science predictive control over deleterious results. Behind pervasive slogans of "scientific breakthrough", "technological substitutions" and "scientific market innovations", research and development are, in fact, reversed into mechanical servant functions to life-blind demands and private moneysequence gain.

The response may continue to be that this is "the only way science can get funded", but this assumption is as false as the rest. Most of the funds for private-profit research are paid from public budgets - from scientific training through massive subsidies and direct research funds, to free major facilities on the campuses of public universities. Scientists and scientific communities are the central managers of science curricula, methods, and protocols within these institutions, as well as highly placed inside governments and policy-making bodies, and are in a position to serve true rather than false science; just as rational decision researchers in philosophy, psychology and economics are free to be life-coherently rational rather the opposite.

In the end, without sound standards of objective setting, design and control to ensure integrity of funding, impartiality of research, and predictive capacity against harm, no rational or scientific validity is possible. Scientific rationality without regulating standards to select for life-enabling rather than life-disabling objectives, and means which are consistent with them, is neither reason nor science. It is life-blind machination under a mask, and its many wearers have deserted both science and rationality in their name. 


\section{References}

Deleuze, Gilles, 1977, Anti-Oedipus: Capitalism and Schizophrenia, New York: Viking Press.

Gauthier, David, 1986, Morals by Agreement, Oxford: York: Oxford University Press.

Harvey, David, 2005, A Brief History of Neoliberalism, New York: Oxford University Press.

International Forum on Globalization (IFG), 1998, The Siena Declaration On the Crisis of Economic Globalization, Siena, Italy, September, 1998.

Marx, 1859, Preface to An Introduction to the Critique of Political Economy in Marx and Engels Collected Works, Volume 29, New York: International Publishers.

Marx, Karl, 1867, Capital Volume 1, in Marx and Engels Collected Works, New York: International Publishers.

McMurtry, John, 1998, Unequal Freedoms: The Global Market as an Ethical System. Toronto and Westport CT: Garamond Press and Kumarian Press.

McMurtry, John, 1999, The Cancer Stage of Capitalism, London: Pluto Press.

McMurtry, John, 2002, Value Wars: The Global Market versus the Life Economy, London: Pluto Press.

McMurtry, John, 2007, "Explaining the Inexplicable: Anatomy of an Atrocity", James H. Fetzer (ed), The 9-11 Conspiracy, pp. 221-290, Peru, Illinois: Carus Press.

McMurtry, John, 2007, "The Postmodern Voice of Empire: The Metalogic of Unaccountability", 2007, in Revathi Krishnaswamy and John Hawley, Minneapolis: University of Minesotta pp. 228-238.

Meadows, Donella L., Meadows, Dennis L, Randers Jørgen, Behrens III, William H., 1972, The Limits to Growth: A Report for the Club of Rome's Project on the Predicament of Mankind, New York: Universe Books.

Miller, Peter and Westra, Laura 2002, Just Ecological Integrity: The Ethics of Planetary Life, Boston: Rowman \& Littlefield.

Mirowski, Philip, 2000, Machine Dreams, Cambridge: Cambridge University Press.

Pareto, Vilfredo, 1971 [1906], Manual of Political Economy, New York: A.M. Kelley.

Rawls, John, 1967, A Theory of Justice, Cambridge Mass: Harvard University Press.

Sumner, Jennifer, 2005, Sustainability and the Civil Commons: Rural Society in the Age of Globalization, Toronto: University of Toronto Press.

Weisbrot, M., Baker, D., and Rosnick, D, 2006, "The Scorecard on Development: 25 Years of Diminishing Progress", International Journal of Health Services 36,2: 211-234.

World Commission of the Environment and Development, 1986, Our Common Future, New York: Oxford University Press. 